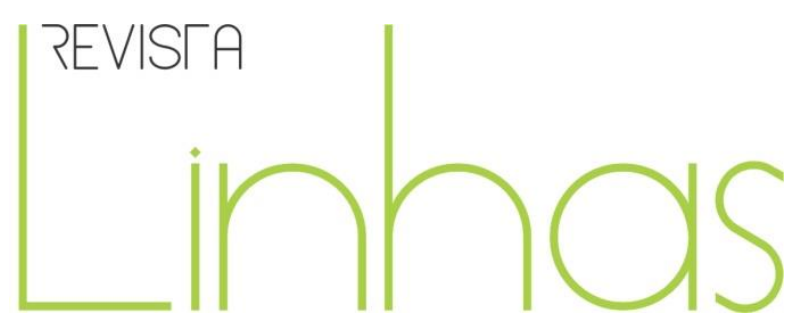

\title{
Estudar sua família para explorar o mundo social: a respeito de uma experiência pedagógica franco-brasileira
}

\begin{abstract}
Resumo
Nós apresentamos aqui uma experiência conduzida com estudantes de ciências humanas e sociais de duas universidades inseridas nos subúrbios das cidades de São Paulo e de Paris. O interesse destes estabelecimentos é que eles recebem estudantes de origem popular com uma grande parte deles cujos pais não fizeram curso superior. $O$ objetivo foi experimentar dispositivos pedagógicos mais motivantes visando a iniciar o estudo da sociologia pela pesquisa. Esta experiência pedagógica é rica antes de mais nada para o professor que por meio dos estudantes viaja para meios sociais aos quais ele não teria acesso. No que tange aos estudantes, este dispositivo conduz à uma forma de socioanálise lhes permitindo se lançar em uma apropriação reflexiva de sua história familiar. No momento em que os gestores apressados desejam racionalizar 0 trabalho pedagógico reduzindo-o a uma série de indicadores quantitativos, nos parece essencial retomar a reflexão pedagógica coletiva de forma à encorajar as experimentações.
\end{abstract}

Palavras-chaves: Ensino de sociologia. Democratização do acesso ao ensino superior. Árvores genealógicas.

\author{
Charles Soulié \\ Université Paris 8 Vincennes-Saint- \\ Denis - França \\ charles.soulie@neuf.fr \\ Graziela S. Perosa \\ Universidade de São Paulo - USP - \\ São Paulo/SP - Brasil \\ grazielaperosa@yahoo.com.br
}

\footnotetext{
Para citar este artigo:

SOULIÉ, Charles; PEROSA, Graziela S. Estudar sua família para explorar o mundo social: a respeito de uma experiência pedagógica franco-brasileira. Revista Linhas. Florianópolis, v. 21, n. 45, p. 78-99, jan./abr. 2020.
} 


\title{
Exploring the social world by studying your family: on a Franco- Brazilian pedagogical experiment
}

\begin{abstract}
We present here an experience conducted with students of humanities and social sciences of two universities inserted in the suburbs of the cities of São Paulo and Paris. The interest of these establishments is that they receive students of popular origin with a large part of them whose parents did not have an undergraduate degree. The aim was to experiment with more motivating pedagogical devices in order to begin the study of sociology through research. This pedagogical experience is rich above all for the teacher who travels through the students to social environments to which he or she would not have access. With regard to students, this device leads to a form of socioanalysis allowing them to engage in a reflective appropriation of their family history. At a time when hasty managers wish to rationalize pedagogical work by reducing it to a series of quantitative indicators, it seems essential to us to resume collective pedagogical reflection in order to encourage experimentation.
\end{abstract}

Keywords: Teaching sociology. Democratization of access to higher education. Genealogical trees. 
As transformações contemporâneas do ensino superior, de suas funções sociais e, de maneira correspondente, aquelas dos mundos dos estudantes e dos professores, incitam muitos professores do ensino superior e, especialmente, os novos ingressantes na profissão, a revisitar suas práticas pedagógicas tradicionais, a fim de buscar novas dinâmicas de trabalho com os estudantes. Neste artigo, apresentamos uma experiência pedagógica, conduzida desde 2015, com estudantes de graduação de duas universidades. A primeira é a Universidade de Paris 8 Vincennes Saint-Denis, localizada em Seine-SaintDenis, na França, no departamente de sociologia e antropologia, o qual recebe uma grande parcela de seus estudantes de origem popular e de imigrantes. Em uma disciplina optativa para o terceiro ano, abordamos o tema da « escolha do cônjuge ». A segunda é a Escola de Artes, Ciências e Humanidades da Universidade de São Paulo, situada em um subúrbio da capital paulista, no Brasil, e que recebe estudantes de origem claramente mais popular do que em outras unidades da USP, sobretudo, se comparados às carreiras consideradas mais nobres dessa universidade. No primeiro ano, eles são inscritos em um ciclo básico interdisciplinar que inclui a disciplina de "Psicologia, educação e temas contemporâneos » na qual se desenvolve esta experiência.

O interesse nessas instituições é que elas acolhem, nos dois casos, estudantes de origem popular, com uma proporção importante de estudantes de primeira geração, ou seja, cujos pais não fizeram ensino superior. A proporção de « herdeiros » (Bourdieu \& Passeron, 1964) é, portanto, particularmente baixa; os resultados escolares, muitas vezes, decepcionantes, estimulando assim os professores a saírem da rotina das aulas magistrais e a experimentar dispositivos pedagógicos que possam ser mais motivantes para os estudantes e para os próprios professores, visando principalmente, iniciá-los em verdadeiras pesquisas: o que quer dizer, mobilizar conceitos sociológicos, antropológicos e psicológicos, no mundo à sua volta. E dessa forma, ao sair da relação, geralmente, estritamente escolar e pouco original que possuem face à teoria, e permitindo ao professor, de escapar ao breviário metodológico normativo, para o qual derivam espontaneamente os cursos de metodologia tradicionais ${ }^{1}$.

Essa pedagogia precoce pela pesquisa nos conduz a articular o ensino de autores,

\footnotetext{
${ }^{1}$ Em relação a isso, Auguste Comte escreveu : «O método não é suscetível de ser estudado separadamente da pesquisa na qual ela é empregada: ou, se assim for, não é mais do que um estudo morto, incapaz de fecundar o espírito à quem se destina » (citado por Bourdieu et al, 1973, p. 11).
} 
métodos e teorias em torno de uma pesquisa de campo. Em especial, o objetivo consiste em levar os estudantes a estudarem a escolha do cônjuge em sua família, mobilizando ferramentas, com potencialidades metodológicas e epistemológicas particularmente fortes, no caso, as árvores genealógicas ${ }^{2}$. Ao solicitar aos estudantes a construção da árvore genealógica de sua família - e depois de estudar a homogamia dos casais, em função das gerações e das linhagens -, tínhamos um duplo objetivo. Levá-los a se apropriar de técnicas de objetivação elementares que lhes permitissem «tratar os fatos sociais como coisas». E, portanto, de ativar, desenvolver neles, e em um campo particularmente sensível e que eles acreditam conhecer bem, ou seja, suas famílias, disposições para pesquisa33. Por outro lado, ainda que nesta experiência a separação entre reflexão metodológica, objeto de estudo e relação com o objeto, seja um pouco formal, procuramos fazê-los apreender as lógicas homogâmicas, em geral, sociais e históricas. Lógicas frequentemente desconhecidas mas, que a confecção e o estudo das árvores e, depois, os pequenos quadros estatísticos que produzem, ainda que relativos à uma amostra limitada, mas racional de casais, permitem objetivar.

O propósito deste artigo não é sintetizar os trabalhos produzidos pelos estudantes mas, sobretudo, refletir sobre os efeitos pedagógicos e sociais desse exercício. É, portanto, um retorno reflexivo a essa experiência que faremos, apresentando, inicialmente, os dois contextos nos quais elas ocorrem. Depois de apresentar o dispositivo mobilizado, nós procuramos descrever a recepção deste trabalho universitário singular pelos estudantes e por seus pais. O que, para concluir, nos conduzirá a refletir sobre a utilidade social e política das ciências sociais.

\section{Duas instituições « modernas », mas periféricas}

Em função das dificuldades históricas do Brasil em matéria de difusão da instrução (no Brasil, a escola obrigatória data da década de 1930 e a ampliação do acesso ao ensino fundamental e ao ensino médio ocorreu por volta de 1990), a França e o Brasil possuem

\footnotetext{
${ }^{2}$ Ou como escrevia W. H. Rivers: « o método genealógico torna possível o estudo de problemas abstratos a partir de uma base concreta» (artigo reproduzido em Ben Hounet, 2005, p. 80).

${ }^{3}$ A experiência apresentada aqui pode ser aproximada daquela conduzida por Nicolas Jounin, com os mesmos estudantes de Paris 8 (JOUNIN, 2014).
} 
sistemas escolares bem diferenciados. Apesar dessas diferenças, esses países partilham alguns traços em comum. Por exemplo, a subdivisão do ensino superior em duas vias paralelas. No Brasil, as universidades públicas, bastante seletivas, se opõem à massa das faculdades privadas e, na França, temos a oposição entre as "grandes écoles » e as universidades, característica do sistema francês ${ }^{4}$. Outro traço comum: os dois países lançaram políticas públicas visando democratizar o acesso ao ensino superior. Assim, tanto a Universidade de Paris 8, como a Escola de Artes, Ciências e Humanidades da USP foram criadas com essa finalidade pelo Estado, em contextos caracterizados pela massificação do acesso ao ensino secundário e pelo aumento do número de estudantes nesse ciclo do ensino. Esse número dobrou na França dos anos de 1960, dando origem à criação do Centro Experimental de Vincennes (hoje, Universidade de Paris 8), em 1968. No Brasil, entre os anos de 1960 e 1970 houve um aumento de 500 mil estudantes universitários 5 . Depois, esse número dobrou novamente entre 2000 e $2010^{6}$. A Escola de Artes, Ciências e Humanidades da USP teve início em 2005, nesta segunda onda de expansão universitária no Brasil.

A Universidade de Paris 8 e a Escola de Artes, Ciências e Humanidades da USP se distinguem também pelo tipo de formação que propõem. A primeira foi criada no movimentado ano de 1968 e que se apresentará como uma « anti Sorbonne », abrindo-se massivamente aos estudantes, mesmo àqueles sem a conclusão do ensino secundário, assim como aos trabalhadores, e se constitui em um dos espaços para o desenvolvimento de novas carreiras; na época, sociologia, psicologia, artes, psicanálise, ciências da educação, urbanismo, sistemas de informação, administração econômica e social, etc.7

\footnotetext{
${ }^{4}$ De acordo com o Censo do Ensino Superior (MEC/2011), as universidades públicas brasileiras recebem apenas $26 \%$ dos estudantes universitários e $74 \%$ são recebidos nas faculdades privadas, conhecidas, em muitos casos, por serem menos seletivas do ponto de vista escolar e social (Cf. Perosa, Costa Taline de Lima, 2015).

${ }^{5}$ No Brasil, assim como na França, esses anos foram caracterizados igualmente pela feminização do público estudantil. A esse respeito, para o caso brasileiro, consultar Barroso \& Mello (1979); para a França (Baudelot, Establet, 1992).

${ }^{6}$ A pesquisa realizada pelo IPEA (Instituto de Pesquisas Econômicas Aplicadas), Evolução do acesso de jovens ao ensino superior no Brasil, descreve bem o crescimento do número de estudantes do ensino superior, entre 2000 e 2010 (Cf. Corbucci, 2014). Durante esse periodo, a proporção de jovens escolarizados, entre 18 e 24 anos, passou de $9,1 \%$ a $18,7 \%$, sabendo que no Brasil essa baixa taxa de acesso ao ensino superior é resultado da acentuada desigualdade social que caracteriza o país. Assim, entre os jovens de 18 a 24 anos vindos de famílias do quintis mais altos de renda, as taxas de acesso são próximas daquelas dos países da OCDE. Fonte: http://www.ipea.gov.br/blog/?p=2287.
}

7 Sobre a história desta universidade (Soulié (dir.), 2012) e (Berger et ali, 2015). 
Entretanto, em 1980, sua transferência autoritária para Saint-Denis contribuirá para lhe assegurar um público mais popular, dentre os quais uma proporção crescente de filhos de imigrantes e dentre eles, uma forte proporção de estudantes estrangeiros originários das antigas colônias francesas (Magreb e África do Norte). O que, ainda hoje, faz dela a universidade mais « estrangeira » da França e condiciona fortemente nossa experiência, contribuindo inclusive para lhe conferir uma dimensão etnológica.

A criação da Escola de Artes, Ciências e Humanidades da USP e sua implantação em um distrito industrial de São Paulo foi resultado de uma política de expansão do ensino superior e do objetivo anunciado de criar uma unidade nova da USP ${ }^{8}$, menos elitista do que as carreiras da antiga instituição. Foram propostas graduações pluridisciplinares, como Ciências da Natureza, Gerontologia, Educação Física e Saúde, Gestão Ambiental, Gestão de Políticas Públicas, Lazer e Turismo etc. Como carreiras novas, elas atraem também novos estudantes, que se orientam para graduações percebidas como "profissionalizantes ", o que contribui para conferir uma posição um pouco ambígua a essa instituição de ensino superior no espaço universitário de São Paulo9. De fato, trata-se de uma universidade pública e, portanto, prestigiada, mas acadêmica e simbolicamente dominada porque oferece formações sem tradição acadêmica $^{10}$.

Para concluir, podemos dizer que a posição estrutural ocupada por esses dois estabelecimentos os predispõe a assumirem-se como lócus de experimentações pedagógicas, assim como de pesquisas interdisciplinares, opondo-se, portanto, à rotina pedagógica e científica dos estabelecimentos de ensino mais antigos e mais centrais na cidade, organizados em torno de disciplinas canônicas, com um recrutamento de estudantes, do ponto de vista social e escolar, mais homogêneo, com um corpo docente mais velho e mais masculino, e por isso mesmo, mais seguro de sua dignidade e legitimidade acadêmica. De fato, a história desses estabelecimentos periféricos mostra que inicialmente eles serão pensados como espaços de experimentações pedagógicas,

\footnotetext{
${ }^{8}$ Sobre a história da Universidade de São Paulo, consultar, (Cardoso, 1982).

9 Este aspecto da definição dos cursos foi abordado em um trabalho precedente: Perosa et. all., 2011.

${ }^{10}$ Fritz Ringer descreveu bem esta fronteira simbólica que atravessa os sistemas de ensino: «o homem instruído aparece como uma personalidade autônoma, perfeitamente cultivada e sua verdadeira educação se distingue de suas sucedâneas vulgares que são as « simples formações práticas » (Ringer, 2003, p. 6).
} 
valorização do «protagonismo » dos estudantes; o ensino em pequenos grupos, uma maior proximidade entre professores e alunos, com a utilização de tecnologias educativas « modernas », interdisciplinaridade e propondo-se a uma abertura maior para o entorno do campus.

\section{Um dispositivo pedagógico bem delimitado}

No quadro de uma disciplina semestral de graduação, com 13 aulas no caso francês e, 15 no caso brasileiro, propomos aos estudantes estudarem a questão da escolha do cônjuge em sua família. Na primeira aula, e depois de explicitar nossos objetivos, tanto científicos quanto pedagógicos, apresentamos um protocolo de quatro páginas reunindo o conjunto de informações e recomendações, detalhando também o calendário de atividades. Este protocolo, que cresceu consideravelmente ao longo dos anos, irá precisar também as atividades a serem entregues e nos permitirá lembrar de certas exigências elementares em matéria de apresentação, ortografia, etc. Parece-nos que esse roteiro transmite segurança para muitos estudantes que experimentam algumas dificuldades para se distanciar do objeto estudado ou se angustiam com a ideia de se perder nos meandros de uma história familiar, mais ou menos, delicada ou complicada.

A primeira parte do trabalho deve ser entregue em duas semanas, com base no que eles já conhecem, e portanto, sem passar pelos pais (mas muitos o fazem...). Nesse primeiro exercício, os estudantes apresentam sua família no sentido mais amplo, informando o número de pessoas, a composição social, a distribuição espacial, o local de moradia etc. ${ }^{11}$ Apresentam o que sabem de antemão das circunstâncias do encontro entre seus pais e de seus avós e anunciam a maneira pela qual pretendem coletar os dados necessários para a confeção da árvore genealógica. Entre as informações que nos transmitem na primeira etapa, estão o local e ano de nascimento, casamento, morte de cada membro da família (pais e avós), seu nível educacional, lugar de residência, sua profissão, religião, línguas faladas e outros elementos biográficos que julgarem pertinentes.

\footnotetext{
${ }^{11}$ Os estudantes que desejarem, podem trabalhar com uma família que não a sua. Poucos estudantes optam por isso e, quando o fazem, se interessam pela família de amigos, namorados ou cônjuges. Nesses casos, os resultados são menos interessantes.
} 
No caso francês, como o número de estudantes é significativamente menor (40 alunos), este primeiro trabalho é objeto de um primeiro retorno individualizado com cada estudante. O interesse dessa reunião é permitir «acertar os ponteiros» com os estudantes mais distantes das expectativas acadêmicas em matéria de ortografia, apresentação e do volume de trabalho esperado. Nos permite, ainda, discutir com cada estudante as particularidades de sua família e, por vezes, de sugerir um embrião de problemática a ser aprofundada (casamentos precoces, profissionalização ou não das mulheres, interrupções do trabalho feminino ligadas aos cuidados da família, etc). Nessa ocasião, distribuímos uma síntese de 40 páginas constituída de extratos de trabalhos realizados por estudantes de anos anteriores e modelos de quadros estatísticos que foram elaborados no estudo de suas famílias. No caso francês, transmitimos, ainda, os quadros relativos à questão da homogamia dos pais dos estudantes de graduação da Universidade de Paris 8, produzidos por meio de uma pesquisa em dez cursos de graduação com questionário $(n=1594)$.

No caso brasileiro, o número de alunos é cinco vezes maior $(n=200)$, o que torna impraticável atendê-los individualmente. Entretanto, organizamos um retorno coletivo a partir dos dados recolhidos em anos anteriores, já que o grande número de alunos permite tratar os dados estatisticamente. Em seguida, iniciamos uma reflexão coletiva com base nessas informações, em especial, comparando origens geográficas, nível de educação em duas gerações, idade em que se casaram (por sexo), idade em que começaram a trabalhar, buscando apresentar uma visão de conjunto das famílias a fim de que o estudante reflita sobre as características de sua família em relação às demais.

Esses dados, ainda em fase de tratamento, são apresentados em gráficos simples, mas eficazes, que nos permitem discutir em sala de aula uma série de movimentos históricos e sociais que incidiram sobre suas famílias, tais como os fluxos migratórios, a expansão da escolarização, as diferenças notadas em termos de idade do casamento, idade em que começaram a trabalhar, nível de escolaridade, as diferenças notadas entre os sexos, etc. Alguns estudantes brasileiros procuram a professora ao final da aula, preocupados com algumas particularidades de suas famílias que os afligem para a realização do trabalho (morte recente de um dos progenitores, rupturas familiares, dispersão geográfica da família, etc). 
O trabalho final, acompanhado da árvore genealógica, deve ser entregue no fim do semestre. Em relação à confecção da árvore, deixamos os estudantes livres para construírem a representação gráfica que lhes parecer mais interessante, proibindo apenas o uso de programas de genealogia disponíveis on line. Com efeito, sublinhamos que nos parece essencial que os estudantes se confrontem na prática com os problemas de representação gráfica de seu universo familiar, que lhes remetem às suas particularidades e também à construção do objeto. É precisamente esta aliança do «fazer » e «refletir » ao fazer, ou se preferirmos, de «pensar com as mãos », que nos parece particularmente preciosa nessa experiência pedagógica e que se reflete na imaginação que os estudantes investem na confecção de suas árvores.

\section{Primeiras lições de método}

Se o anúncio do tema da pesquisa aos estudantes pode lhes dar a ilusão de um trabalho fácil de fazer, a precisão das informações solicitadas faz com que compreendam rapidamente a dificuldade da proposta. De fato, o conhecimento prático, e portanto, aproximativo do qual dispõem revela-se insuficiente e o recurso aos informantes, arquivos da família, como álbuns de fotografia e documentos diversos, se impõem rapidamente. Esta exigência de precisão leva a um primeiro distanciamento e os estudantes descobrem, então, como já sugeria Hegel, que o familiar, não é tão conhecido como parece. E que os «dados » não estão dados, mas são produzidos e até mesmo conquistados. Eles descobrem também que as entrevistas face a face ou coletivas, durante os almoços familiares, são frequentemente mais ricas do que as entrevistas por telefone, ou contato por e-mail ou facebook.

O que não impede que muitos utilizem as novas tecnologias que Ihes permitem, por exemplo, solicitar informações mais facilmente às pessoas geograficamente distantes ou em grande número. Assim, uma estudante brasileira criou o seu próprio « Google docs » com um quadro com as informações solicitadas e o enviou por WhatsApp à sua família. Sabendo que as famílias estão desigualmente conectadas à internet no Brasil e na França. Se os estudantes de famílias cosmopolitas e mais favorecidas, com membros vivendo no exterior, estão habituadas ao uso do Skype, as famílias que vivem em regiões 
rurais podem não ter acesso fácil à internet e os custos das ligações telefone, por vezes, são altos.

Em geral, para obter as informações solicitadas, os estudantes recorrem às suas mães, que possuem em geral uma memória mais precisa em relação a datas do que seus pais. E se dão conta de uma divisão ordinária do trabalho de manutenção das relações familiares, que faz das mulheres as especialistas da história familiar. Mas, muito rapidamente, os estudantes recorrem também a outros informantes como avós e mesmo tias mais distantes.

Alguns estudantes de origem social mais alta, enraizados há várias gerações no interior ou na capital, conseguem ir mais longe no tempo e recolher rapidamente uma quantidade enorme de informações. Por vezes, sentem-se atolados em uma massa enorme de informações recolhidas, principalmente, quando herdam uma árvore genealógica feita por terceiros, mas raramente em uma perspectiva sociológica. Inversamente, os estudantes membros de famílias geograficamente dispersas, separadas seja em razão das migrações ou de conflitos familiares, encontram maiores dificuldades. É o caso de muitos estudantes estrangeiros da Universidade de Paris 8, em especial dos africanos, cujas famílias ficaram em seu país de origem. Sabendo que o estado civil de pais e avós em seus países podem ser aproximativas (datas de nascimento, morte, casamento, etc), dependentes da memória familiar, ou ainda, ancoradas em grandes eventos climáticos, históricos, dentre outros.

Em Paris 8, universidade cujo recrutamento é particularmente cosmopolita, um dos resultados mais interessantes é o tamanho das famílias. Assim, em 2016, de 39 estudantes, $43 \%$ declararam ter uma família que possui menos de 30 membros, $26 \%$ entre 31 e 99 membros e 30\% igual ou superior a 100. Contamos, ainda, cinco famílias que possuem entre 200 e 300 pessoas e uma superior a 300. Ao mesmo tempo, essas famílias são mais ou menos dispersas, sendo que $14 \%$ dos estudantes declararam que suas famílias são concentradas em um só país, 32\% em dois países e, $54 \%$ se dispersam em três países ou mais.

Inversamente, no Brasil, os estudantes estrangeiros são pouco presentes. É preciso voltar à geração dos bisavós, em geral, para identificar as grandes correntes migratórias internacionais do final do século XIX e início do século XX, especialmente a 
imigração europeia (espanhóis, portugueses, italianos), assim como japoneses, libaneses, etc. Neste país continental, as migrações internas (especialmente do nordeste, mas também de Minas Gerais e de outros estados para São Paulo) são um dos principais fatores de diferenciação interna da população. De mesma maneira, o tamanho das famílias diminui fortemente ao longo das gerações, fenômeno que ocorreu na maior parte dos países do mundo. Chama muita atenção dos estudantes brasileiros o aumento da escolaridade em suas famílias e a maneira pela qual as diferenças de gênero incidem sobre as trajetórias. Na geração dos avós, nascidos por volta de 1941, 53\% dos avós possuem apenas o ensino primário e 5,7\% deles concluíram o ensino superior. Na geração dos pais, nascidos por volta de 1970, 40,2\% dos pais e $35 \%$ das mães possuem o ensino superior.

As questões relativas à morfologia das famílias são indissociáveis daquelas relativas à sua definição. Com esse exercício, muitos estudantes começaram a refletir sobre a questão do perímetro de sua família e a compreender o interesse da distinção entre «família prática » - quer dizer que eles encontram e conhecem - e a «família » no papel, mais ou menos fictícia, o que permite que fabriquem a árvore genealógica. É a oportunidade, então, para tomar consciência do caráter mais ou menos prescritivo, e arbitrário, dos modelos de árvores habitualmente empregados, fenômeno particularmente sensível para as famílias «recompostas » ${ }^{12}$. Dessa forma, um estudante brasileiro se perguntou como representar uma família na qual o pai se casou três vezes e teve filhos nos três casamentos.

Em função das especificidades de cada família (tamanho, divórcios, recasamentos, agregados, e no caso das famílias africanas, da prática da poligamia etc.), os estudantes encontram algumas dificuldades para a construção de suas árvores, a partir das quais precisam fazer escolhas como uma maneira de compreender na prática o príncípio bachelardiano, segundo o qual toda representação é construção. E, por essa experiência, começar a deixar a evidência naturalista, e afetivamente tão poderosa, na qual muitos estão ainda bastante imersos, em especial, no que concebe a família como o lugar do

\footnotetext{
${ }^{12}$ Como sublina Pierre Bourdieu: "Em todos os usos dos conceitos classificatórios, como aquele de família, nós nos comprometemos de uma só vez com uma descrição e uma prescrição que não se apresenta como tal porque ela é (mais ou menos) universalmente aceita e admitida como natural: nós admitimos tacitamente que a realidade à qual damos o nome de família, e que classificamos como 'verdadeiras' famílias, corresponde à uma família real." (Bourdieu,1993, p. 33).
} 
amor obrigatório.

Essas questões de morfologia, de definição do objeto, ruptura com as evidências sociais do senso comum que agem frequentemente como injunções inconscientes, revelam-se indissociáveis do grau de integração da instituição familiar. Por exemplo, descrevendo a união dos pais e avós, muitos estudantes de origem africana fizeram referência aos «casamentos arranjados» e identificaram diferenças de idade impressionantes entre os cônjuges. Esse tipo de união, no Brasil, apareceu de outra maneira; como entre as famílias japonesas, e surpreendeu uma aluna que, no ato da entrevista com os avós, se deu conta de que aquele casamento havia sido arranjado: « Eu pensava que isso era uma coisa mais antiga... ». Vê-se, assim, que uma mesma palavra «família» designa instituições sociais muito distintas e isso tanto em termos morfológicos, quanto em termos das pressões que elas exercem sobre os seus membros, por exemplo, no que diz respeito à escolha do cônjuge. Entretanto, quando os estudantes evocam essas pressões, é frequentemente para dizer que eles, atualmente, não sofrem mais com essas questões e que a sua geração é muito mais « livre » do que as precedentes.

\section{Famílias mais ou menos típicas}

Um dos principais interesses deste trabalho é permitir que os estudantes comecem a descobrir o poder das lógicas homogâmicas, as quais são mais ou menos explicitadas em seus trabalhos. Porque muitas vezes as tendências homogâmicas são tão profundamente enraízadas, que fazem com que as uniões se dêem no interior da mesma classe social, com a mesma idade, o mesmo nível escolar, e de maneira mais ou menos equivalente, com mais ou menos a mesma cor da pele, entre brancos ou pardos e negros, mas também entre crentes e ateus, moradores de uma determinada região, etc., que são tão normais e evidentes que nós não as enxergamos. E, portanto, que jamais pensamos em fazer um quadro estatístico que inclua por exemplo a variável cor da pele, religião, etc. simplesmente porque encontraríamos quase 100\% das uniões homogâmicas. E é por isso, inclusive, que quando um casal na família se desvia dessa rota, ele abre espaço para outras alianças matrimoniais possíveis. Muitas famílias ou gerações são 
« monocromáticas », « monorreligiosas », ou « monoescolares ».

A árvore genealógica de tipo ascendente, geralmente construída pelos estudantes, lhes permite comparar sistematicamente os casais da mesma geração (leitura horizontal), mas também reinserir cada união na cadeia de uniões constitutivas de cada família (leitura vertical) e, por exemplo, comparar as linhagens entre elas, o que lhes permite desenvolver uma perspectiva dinâmica, dando espaço para as evoluções sóciohistóricas. A questão da escolha dos cônjuges revela-se, assim, indissociável das questões de mobilidade social e da trajetória familiar. Muitos estudantes descobrem em suas famílias os traços correspondentes do «romance nacional » especialmente descritos pela história, pela literatura, ou evidenciados pelas ciências sociais. Por exemplo, do lado francês, encontramos as trajetórias das pessoas do interior que "sobem para Paris », migração interior hoje eclipsada pelas migrações internacionais.

O mesmo fenômeno se observa em São Paulo, em que $41 \%$ dos pais nasceram na capital, $18 \%$ vieram do interior do estado e $16 \%$ do nordeste e; dentre os quais $15 \%$ dos avós são nascidos em São Paulo. A família brasileira que corresponde ao « romance nacional » é composta por uma geração de avós (nascidos entre 1930/1940) trabalhadores rurais, com baixa escolaridade, vindos do nordeste rural e que vieram trabalhar como operários ou empregadas domésticas na rica e industrializada cidade de São Paulo ${ }^{13}$. O êxodo rural, o aumento generalizado da escolarização, o crescimento da atividade profissional feminina, etc., permitem observar fenômenos de ascensão social, mais ou menos discretas, ou especatulares, com filhos de agricultores ou operários que chegam ao ensino superior e tornam-se funcionários públicos, enfermeiras, etc., contribuindo para esse movimento de ascensão social das famílias. Assim, muitos estudantes descobrem a estabilidade social, ou imobilidade relativa de sua família, e mesmo o seu declínio. Um estudante brasileiro escreveu : «Com este trabalho, eu me dei conta de que minha família sofreu um declínio social... Eu nunca tinha pensado nisso...»

Algumas famílias, entretanto, são menos típicas. Diante de configurações familiares mais contingentes ou que remetem a problemas que parecem de outras

\footnotetext{
13 Deste ponto de vista, o estudo da antropóloga Elisabeth Linhares sobre três gerações de famílias de origem rural do Rio de Janeiro mostra bem como se deu a experiência educativa para esta mesma geração (nascidos por volta de 1940) de agricultores, onde o trabalho precoce e a ausência de escolas eram a regra (Linhares, 2008).
} 
disciplinas (psicologia, psicanálise, etc.), não é fácil encontrar os princípios para orientar os estudantes a construírem seu trabalho; nesse caso, nós os orientamos a seguir recolhendo as informações possíveis que Ihes permitam construir minimamente essa representação de suas famílias. Pensamos, por exemplo, no caso das famílias abaladas pela morte prematura de um dos pais, pela repetição de eventos traumáticos, constituídas apenas por mulheres, ou ainda, em que a religião, o esporte, o mundo artístico, ou a militância política, exercem o papel de uma escola paralela, lugar de acumulação de capital social ou de possibilidades de abertura para outros universos.

Um bom indicador tanto do grau de apropriação desse dispositivo pedagógico, como do grau de conceitualização de suas histórias familiares pode ser apreendido pelo título dado ao trabalho pelos estudantes. Estes vão desde os mais rasos : «Minha família », « Trabalho sobre a escolha do cônjuge », «Árvore genealógica da família X » aos mais problematizados e personalizados, revelando o início da construção de um objeto de estudo: "Da homogamia rural à homogamia urbana », «Uma família desenraízada », « Declínio e reconstrução da dinâmica familiar », etc.

\section{Poder e desejo de aprender}

Paralelamente à dificuldade de escrita, maior ou menor, o que em si mesmo já é um fator poderoso de desigualdade entre os estudantes, a capacidade de apreender a história familiar e de produzir uma imagem sociologicamente construída é também desigualmente distribuída entre os alunos. Essa apreensão da história familiar possui também suas condições sociais, afetivas, etc., de possibilidade. Assim, inserindo uma referência a essas dificuldades, uma estudante francesa atribuiu como título do seu trabalho «O caos: a família, escola de simpatia, de prazeres e de dores em comum», cujo pai teve filhos com mais de dez mulheres, o que implicou para ela ter muitos meio-irmãos, revela bem a importância da dimensão afetiva da instituição familiar. Dimensão que aparece também no grafismo de algumas árvores genealógicas fabricadas pelas meninas nas quais, por exemplo, cada união é simbolizada por um coração.

Pensamos, ainda, no peso das histórias « de família », bem como nos « segredos de família », afetivamente muito carregados e que um trabalho como este faz reaparecer. 
Disso derivam algumas reações de defesa de algumas famílias. Um membro de uma família na França ao ser abordado sobre o trabalho aconselha o estudante « ocupe-se dos vivos mais do que dos mortos ». As histórias familiares são, portanto, mais ou menos passíveis de serem contadas, o que não facilita o trabalho do pesquisador que pode reprovar a proposta do trabalho, na medida em que ela implica falar de sua família para um terceiro. E, por exemplo, a existência da gravidez antes do casamento evocada indiretamente por algumas avós brasileiras e que precipitou uma migração, ou que esteve na origem de casamentos sem amor, ou ainda, histórias de suícidio, de loucura, de deliquência, ou seja, casos desviantes da norma social, situações que podem deixar a realização deste trabalho mais difícil. No caso brasileiro, observamos que quando o divórcio levou a uma ruptura familiar, os estudantes têm também um sentimento de vergonha. Nas primeiras aulas, em que discutimos a elaboração desse trabalho, alguns estudantes procuraram a professora para falar em particular sobre a situação, o que expressa um certo constrangimento de ver sua árvores reduzida a apenas uma linhagem.

Assim, acontece às vezes, de alunos que comentam com os colegas o caráter « pessoal » da história familiar, mas raramente na presença do professor, e se recusam, contra aquilo que pode ser vivido como uma intrusão da universidade ou do professor, em sua intimidade familiar. A produção de trabalhos sem envolvimento, em que o estudante investe o mínimo possível e o uso, por exemplo, da terceira pessoa para redigir o trabalho podem exprimir isso. Pensamos, ainda, no caso de um estudante francês que na primeira versão do trabalho escreveu que ele achava que não aprenderia nada com a atividade e que realmente, ao final, não descobre muita coisa.

Se em algumas famílias a proposta pode encontrar obstáculos tanto afetivos quanto sociais, que por vezes se deslocam ou se recompõem ao longo do curso, muitos estudantes investem bastante e dão provas de uma engenhosidade metodológica notável, ainda que em condições não muito favoráveis. Pensamos, por exemplo, no caso de um estudante brasileiro, órfão e que vivera toda sua vida em um orfanato e conseguiu realizar um trabalho interessante. Em outros casos, a proposta do trabalho é recebida com entusiasmo e suscita uma verdadeira mobilização coletiva na família. Por exemplo, algumas famílias francesas, principalmente da província, onde a genealogia é um passatempo valorizado e as refeições em família dão lugar a momentos em que se pode 
identificar o prazer de contar sua história e de « se » contar: como as situações em que os pais descrevem com prazer, e com muitos detalhes, as circunstâncias aos olhos encantados de seus filhos. Ou ainda, uma família das Ilhas Maurício, de origem popular, muito entusiasmada com o trabalho e que o qualificou como "um bom trabalho", porque leva os jovens a se interessarem por suas origens e a de seus antecedentes.

Registramos ainda que este trabalho é frequentemente a ocasião de valorizar uma trajetória familiar ascendente ou de «personalidade » ("Minha avó era uma pioneira », «Meu avô era militante no período da ditadura militar »). A fabricação coletiva dessa árvore permite a cada um contribuir para a produção de uma imagem idealizada do grupo, baseando-se nos álbuns de família que registram apenas os grandes momentos da história familiar. De onde deriva ainda uma hagiografia em certos trabalhos, nos quais o estudante torna-se o memorialista do grupo. Esses casos aparecem mais frequentes entre os estudantes que são os primeiros em sua família a ingressarem no ensino superior e são transformados em « intelectuais orgânicos ». De certa forma, tudo se passa como se esse trabalho beneficiasse uma espécie de transferência familiar positiva à instituição escolar.

Notamos, em alguns casos, um investimento desmesurado por parte do estudante que pode ser notado no número de páginas e na confecção de árvores genealógicas imensas, bem desenhadas e coloridas, contendo fotografias de cada membro da família e informações biográficas de cada membro da família, etc., coroados por um título caligrafado, mais ou menos inspirado. Em relação às árvores, é preciso mencionar a inventividade desenvolvida por certos estudantes que os levam, às vezes, à fabricação de verdadeiras obras erigidas em elementos do patrimônio familiar. Uma estudante no Brasil pendurou sua obra na árvore de natal da família. Não raro, após a conclusão do semestre, alguns alunos escrevem ou procuram o professor, no Brasil e na França, para agradecer por essa experiência de reflexão coletiva.

Na Universidade de Paris 8 e em certas famílias de origem cabília da zona rural, observamos o orgulho de exibir uma família numerosa, antiga, unida e «honrada» evidentemente que conduz, muitas vezes, a uma forma de culto dos ancestrais. O que confere uma dimensão mais ou menos « sagrada » a esse exercício e conduz a recalcar, ou fazer desaparecer, os episódios ou os personagens pouco gloriosos da história familiar. Assim, mencionando a censura exercida pelo grupo doméstico, uma estudante 
marroquina esclarece: « Na cultura árabe-muçulmana não é bom falar dos mortos. Diante de qualquer questão sobre um acontecimento cuja reputação do morto é posta em causa, as pessoas respondem: « Fale bem dos seus mortos. »,' "Fale dos méritos dos seus mortos e abstenha-se de seus pecados». A confecção da árvore possui, portanto, uma forte dimensão de performance. Ela é frequentemente associada aos conflitos, mais ou menos explícitos, relativos à « honra » da família, que nos fazem lembrar do uso antigo da genealogia nas famílias reais ou nobres. Essa dimensão de culto à família aparece de alguma forma também nos muitos trabalhos que têm como título « A família Freire », por exemplo.

A importância sociopolítica da questão relativa à genealogia explica por que em algumas culturas a tarefa de contar e atualizar a história familiar é conduzida pelos mais velhos ou por especialistas (memorialistas que fazem, por ocasião da celebração de casamentos, por exemplo, um elogio à cada família), imbuídos da legitimidade necessária para tal. Compreende-se, assim, as dificuldades encontradas por filhos de imigrantes, ou de estrangeiros de origem africana, por ocasião da coleta de informações sobre os casais, em que a constituição do casal é frequentemente um tabu. Esse fenômeno também pôde ser observado no Brasil, em especial, entre as famílias de origem japonesa, como nos explicou uma aluna «não é muito bem visto que os jovens façam muitas perguntas aos mais velhos ». Essa estudante relatou ainda que a entrevista com seus avós foi conduzida com « muita delicadeza, educação, aos poucos ». Esse tato é também necessário para as histórias familiares dolorosas, como nas entrevistas entre as jovens pesquisadoras e suas avós que, frequentemente, foram ocasiões para a descoberta de alguns segredos de família bem guardados e de aproximações inesperadas entre gerações.

Esse pudor nos remete notadamente à rigidez das relações de dominação entre as gerações, entre os sexos, o que vem se alterando ao longo dos anos, mas que prevalece uma relação mais ou menos hierárquica entre pais e filhos, como bem argumenta Norbert Elias (2010), e por fim, do caráter mais ou menos « sagrado » da instituição familiar, o que por vezes, prejudica alguns dos nossos pesquisadores. Essa situação se contrasta fortemente com o modelo familiar dominante, mais igualitário, individualista e psicologizante, incidindo principalmente nas famílias da pequena burguesia, das quais os professores, por sua cultura e posição de classe, são necessariamente mais próximos. 
Em relação à importância atribuída a cada geração ou grupo social para a dimensão "subjetiva », " pessoal », uma avó de origem francesa das classes populares, observou: «Hoje em dia, a gente fala mais da vida pessoal do que quando eu era criança». Em certas famílias de origem africana esse trabalho foi, em alguns casos, associado a um inquérito policial. Uma senhora desconfiou, por exemplo, que a pesquisadora quisesse « enfeitiçá-la » com suas perguntas sobre datas precisas. Tantas exigências nos fazem lembrar, inclusive, do universo burocrático e põem em questão os efeitos sociais e políticos da transcrição do relato oral para a escrita da história familiar.

Esta pesquisa, entretanto, foi percebida por alguns como uma forma de intrusão, mais ou menos intolerável na esfera familiar por parte da universidade, dos brancos, enfim, dos dominantes. Ou como disse esta mãe na França : «Quando os brancos querem observar nossa família (é porque) eles vão dizer que os negros cometem excessos! ». É preciso considerar ainda que algumas práticas são estigmatizadas no ocidente, como a poligamia, a excisão, o casamento entre primos, o que causa certo desconforto entre os estudantes de origem africana.

No que diz respeito à recepção deste trabalho pelos estudantes e, de um modo geral, pelas famílias, uma polaridade se desenha na Universidade de Paris 8. Aquela que opõe às famílias de imigrantes e estrangeiros, mais tradicionais e extensas, frequentemente religiosas, com grande diferença de idade entre os casais e nas quais o divórcio é mais raro, e que se opõem ao modelo predominante das famílias « recompostas », de origem social mais elevada, nas quais pais e filhos são a priori mais sensíveis ao caráter voluntário e construído da relação familiar e que contribui, inclusive, para relativizar a importância da paternidade biológica ${ }^{14}$. Se, para os primeiros, este trabalho foi mais ou menos bem recebido (mesmo se considerarmos que a posição, entre dois mundos, ocupada por parte desses estudantes estrangeiros, principalmente quando eles percorreram uma trajetória escolar de êxito em relação à sua origem social, contribui também para o desenvolvimento de uma forma de lucidez sociológica aguda), vemos que para os segundos, a sociologia, e de um modo geral, o saber desnaturalizante produzido pelas ciências humanas e sociais, responde claramente às demandas de racionalização

\footnotetext{
${ }^{14} \mathrm{O}$ que aparece, principalmente, quando fabricando sua árvore, os estudantes devem escolher representar a família de seu pai biológico ou de seu padrasto.
} 
trazidas pelas transformações contemporâneas da instituição familiar ${ }^{15}$. Parece-nos que o trabalho de construção e desconstrução sociológica de sua história familiar por cada estudante é inseparável de um trabalho sobre os afetos investidos nessa instituição ${ }^{16}$.

\section{Experimentar, pesquisar}

Como se vê, a experiência pedagógica apresentada aqui é de uma enorme riqueza. Primeiro, para o professor que, por meio de seus estudantes, traz metodicamente o mundo social para a universidade e viaja para outros meios sociais, mais ou menos exóticos, aos quais ele jamais teria acesso e o que causa, por vezes, surpresa, desconcerto, emoção, com aquilo que se descobre. Em algumas situações, experimentamos um sentimento de estranheza quase etnológica descobrindo universos, e também configurações familiares que não deixam de nos interpelar. Consideramos, ainda, que esses trabalhos são também uma oportunidade de conhecer nossos estudantes e, a partir daí, ajustar nossas práticas de ensino. Por parte dos estudantes, podemos dizer que esse dispositivo provoca uma forma de socioanálise metódica, relativamente assistida pelo professor se eles tiverem o desejo, a necessidade de se dedicarem à uma forma de apropriação reflexiva de sua história familiar, favorecendo o desenvolvimento de uma relação interessada e, portanto, ativa com o saber.

Esse dispositivo, que mobiliza sistematicamente os recursos pessoais e familiares de cada estudante, rompe também com a igualdade formal e o individualismo postulados pelas modalidades standard de avaliação e não deixa de apresentar algumas questões sobre a avaliação. Efetivamente, ao reconstruir metodicamente as particularidades de cada trajetória familiar e ressituando cada estudante em seu meio social, ele contribui para evidenciar as diferenças e desigualdades sociais de partida, ou seja, ligadas à origem social. Como o trabalho revela o percurso social das famílias, o ponto de partida do estudante, por vezes nos interrogamos se não estávamos avaliando as trajetórias familiares e a implicação com o trabalho.

\footnotetext{
15 Sobre tais transformações, consultar, particularmente, o capítulo de Norbert Elias, “A civilização dos pais". Cf. Elias, 2010.

${ }^{16}$ Por exemplo, a ideia de que o amor não esteja nas origens de uma vida marital, mas que ele possa resultar da convivência, de que o vínculo mútuo se desenvolva com a cohabitação, etc, reaparece em muitos trabalhos de estudantes franceses e brasileiros.
} 
Após a publicação dos Herdeiros, de Bourdieu e Passeron, sabemos que toda avaliação escolar é também uma avaliação social. A fim de ser o mais justo possível, explicitamos a valorização das qualidades formais do trabalho (apresentação, ortografia...) cuja importância foi explicitamente sublinhada nas recomendações para a sua realização. Da mesma forma, fomos atentos ao investimento dos estudantes, à boa vontade escolar que se objetiva, por exemplo, no número de páginas redigidas, na qualidade da árvore genealógica, ainda que, considerando simultaneamente, as desvantagens e handcaps de cada um. Além disso, valorizamos o grau de apropriação dos conceitos transmitidos em curso, a reflexividade exposta no trabalho, a inventividade metodológica, estatística etc., sabendo que no caso francês este trabalho contribui com metade da nota final e a outra metade com uma prova e, enquanto no caso brasileiro, ele corresponde ao total da nota, lembrando que o trabalho é optativo e que eles poderiam decidir fazer uma prova ao final do semestre sem necessidade de justificar essa escolha.

Como todo dispositivo pedagógico, ele também possui os seus limites e produz efeitos perversos. Partir de sua família, da questão da escolha do cônjuge e fabricar sua árvore genealógica para explorar o mundo social é apenas uma maneira, dentre outras possíveis, de estimular os estudantes ao trabalho intelectual. Ao descrever essa experiência pedagógica, nosso objetivo é contribuir para alimentar uma reflexão coletiva a respeito das práticas docentes no ensino superior. Parece-nos que é por meio desse trabalho de experimentação invisível, em geral conduzido solitariamente por cada professor com a « sua turma » que geração após geração, a universidade se adapta aos seus novos públicos e responde às transformações contemporâneas de relação com o saber, articulando especialmente ensino e pesquisa desde os anos iniciais da formação. Em um momento em que os gestores do ensino superior, apressados, desejam racionalizar o trabalho pedagógico, reduzindo-o a uma série de indicadores quantitativos e impondo formas de engenharia pedagógicas extraídas do mundo empresarial, nos parece crucial estimular a reflexão pedagógica de maneira a encorajar e fundamentar as experimentações pedagógicas e dessa forma, alimentar a illusio pedagógica de cada um.

Mais amplamente, esse tipo de experiência faz pensar no papel social e político da universidade, em especial, para a nova geração de estudantes do ensino superior. Parecenos que essa experiência permite aos ingressantes na universidade que se apropriem de 
suas trajetórias, de suas histórias, e por aí, contribui para expandir o espaço de possíveis tanto intelectual, como social e político para que dessa forma ela seja fiel à sua herança humboldtiana, que é de ser um lugar privilegiado para a emancipação pelo conhecimento. Herança que, no quadro das sociedades democráticas, não tem vocação para ser reservada apenas a uma elite.

\section{Referências}

BARROSO, Carmen \& MELLO, Guiomar N. de., "O acesso da mulher ao ensino superior". Cadernos de Pesquisa, 15: 47-75, São Paulo, 1979.

BAUDELOT, Christian \& ESTABLET, Roger. Allez les filles! Paris: Seuil, 1992.

BERGER, Guy, COURTOIS Maurice, PERRIGAULT Colette. Folies et raisons d'une université: Paris 8 De Vincennes à Saint-Denis. Paris: Éditions Petra, 2015.

BEAUD, Stéphane \& WEBER, Florence. Guide de l'enquête de terrain. Paris : La Découverte, 2003.

BEAUD, Stéphane \& WEBER, Florence. Guia para a pesquisa de campo: Produzir e analisar dados etnográficos. Petrópolis: Vozes, 2014.

BOURDIEU, Pierre; PASSERON, Jean-Claude. Les héritiers: les étudiants et la culture. Paris: Minuit, 1964.

BOURDIEU, Pierre, CHAMBOREDON Jean-Claude, PASSERON, Jean-Claude. Le Métier de sociologue, préalables épistémologiques. Paris : Mouton, 1973.

BOURDIEU, Pierre. “À propos de la famille comme catégorie réalisée”. Actes de la recherche en sciences sociales, $n^{\circ} 100$, , 1993.

CORBUCCI, Paulo Roberto. Evolução do acesso de jovens ao ensino superior no Brasil. Brasília, INEP, 2014. Fonte : http://repositorio.ipea.gov.br/handle/11058/3021

ELIAS, Norbert. Au-delà de Freud: sociologie, psychologie, psychanalyse. Paris: La Découverte, 2010.

GARCIA, Sylvia Gemignani; CARLOTTO, Maria Caramez. Tensões e contradições do conceito de organização aplicado à universidade: o caso da criação da USP-Leste. Avaliação (Campinas), Sorocaba, v. 18, n. 3, p. 657-684, Nov. 2013.

JOUNIN, Nicolas. Voyage de classes : des étudiants de Seine-Saint-Denis enquêtent dans les beaux quartiers. Paris : La Découverte, 2014. 
LINHARES, Elizabeth Ferreira. « Escravos na roça, anjos na escola », Revista Tempo Social, vol. 20, n. 1, pp.95-117, 2008.

PEROSA, Graziela Serroni; SANTOS, Gislene Aparecida; Menna-Barreto, Luiz. "Desafios da expansão do ensino superior: a USP no lado Leste da cidade". In: Valéria MAGALHÃES; Ricardo SANTHIAGO (Org.). Memória e diálogo: Escutas da Zona Leste, visões sobre a história oral. São Paulo: Letra e Voz, p. 41-60, 2011.

PEROSA, Graziela \& COSTA, Taline de Lima. “Uma democratização relativa?” Revista Educação \& Sociedade, vol. 36, n¹30, p. 117-137, 2015.

RINGER, Fritz. « La segmentation des systèmes d'enseignement ». Actes de la recherche en sciences sociales, $n^{\circ} 149,2003$.

RIVERS, William Halse, « La méthode généalogique en anthropologie » (1910). In Yazid Ben Hounet, Parenté et anthropologie sociale, Ginko, 2005.

SOULIE, Charles (Org.). Un mythe à détruire ? Origines et destin du Centre universitaire expérimental de Vincennes. Paris: Presses universitaires de Vincennes, 2012.

Recebido em: 06/01/2020 Aprovado em: 29/02/2020

Universidade do Estado de Santa Catarina - UDESC Programa de Pós-Graduação em Educação - PPGE Revista Linhas Volume 21 - Número 45 - Ano 2020 revistalinhas@gmail.com 